\title{
Combined Effects of Late IVC and EGR on Low-load Diesel Combustion
}

\author{
Jonas Sjöblom \\ Chalmers University of Tech.
}

\begin{abstract}
The increasing demand for improved efficiency of diesel engines requires more advanced combustion solutions. These solutions include the use of variable valve timings in combination with more traditional methods such as EGR, turbocharging and advanced injection systems. By modifying the characteristics of the charge air, further hardware optimization becomes possible.

In the current investigation, the effect of late intake valve closing (LIVC) was investigated together with the effect of (external) exhaust gas recirculation (EGR) in a single cylinder heavy duty diesel engine. Different injection timings and injection pressures were investigated. The mass flow of oxygen was kept constant in order to show how the density and temperature of the reactant mixture affect the combustion and emission characteristics.

The combustion results showed that if the oxygen mass flow is kept constant, an EGR approach is more efficient than LIVC in lowering fuel consumption due to the effects of increased cylinder gas flow which improves fuel conversion efficiency. It was shown that the ignition delay for a fixed combustion phasing was independent of EGR but could be increased by LIVC. The peak pressure was more strongly affected by EGR due to the larger gas flow but this response can be reduced by means of LIVC. After compensating for combustion timing effects, the reduced peak pressure was mainly attributed to reduced effective compression ratio resulting from the LIVC.
\end{abstract}

The results show how variable valve timing can be used as one important tool to obtain better combustion characteristics and thus enable more efficient powertrains.

CITATION: Sjöblom, J., "Combined Effects of Late IVC and EGR on Low-load Diesel Combustion," SAE Int. J. Engines 8(1):2015, doi:10.4271/2014-01-2878.

\section{INTRODUCTION}

The world faces grand challenges to mitigate the effects of an un-sustainable usage of fossil fuels. While alternative fuels will become more important, fossil fuel will be a major energy source for transportation in many years to come. Improved efficiency of the internal combustion engines provides one important way to reduce $\mathrm{CO}_{2}$ emissions and present and future legislations will make an important contribution to reduce these $\mathrm{CO}_{2}$ emissions.

There are many ways to improve the efficiency but improved combustion efficiency is often accompanied with high local temperature which results in unacceptably high $\mathrm{NO}_{x}$ emissions. $\mathrm{NO}_{X}$ is mainly formed by the Zeldovic mechanism which is favored by high temperature (as well as oxygen concentration and time). One method to reduce $\mathrm{NO}_{x}$ formation is by lowering the oxygen concentration by means of EGR. The lowered oxygen concentration will also result in lower peak temperature and significant reductions in $\mathrm{NO}_{X}$ formation can be obtained. However, EGR also slows down the combustion rate and the efficiency is not as high as for non-EGR systems. Another way to obtain lower peak temperatures is by obtaining a cooler gas mixture at the time for fuel injection. Even though charge air cooling is commonly applied, the gas compression itself inevitably raises the temperature. Yet another $\mathrm{NO}_{\mathrm{x}}$ reduction strategy is reducing the compression stroke itself by means of changing the timing of the inlet valve closure (IVC). This method was proposed by Ralph Miller in 1957 [1] and it appears in the literature under a variety of names depending on the technical implementation. In this study we will use the name "late Miller" even though "supercharged Atkinson cycle" is also appropriate. Since reduced compression stroke will result in lower amount of air, the volumetric efficiency will be low unless compensated for by a turbocharging system. Until recently, systems for changing the IVC haven't been economically attractive for implementation in heavy duty powertrains, but upcoming regulation changes and the need for more fuel-efficient powertrains have changed this situation. In a current EU project (CORE, CO2 Reduction for long distance transport) [2], different Variable Valve Actuation (VVA) 
systems are being evaluated and promising results are being obtained by coupling the approach with an efficient turbocharging system.

Over-expanded cycles are well established [3] showing an increase in efficiency but with a decrease in IMEP and power density. The Miller cycle has been studied for the Otto-cycle (e.g. $[\underline{4}, \underline{5}])$, the diesel cycle (e.g.[ㅁ, $\underline{7}, \underline{8}, \underline{9}, \underline{10}, \underline{11}, \underline{12}, \underline{13}, \underline{14}])$ or both (e.g. $[15,16])$. The concept has also been studied for alternative fuels (e.g. [17]). Supercharging was already envisaged in the Miller patent, but in cases where fuel efficiency alone is sought the Miller cycle without supercharging (i.e. the Atkinson cycle) is applied, for example in hybrid vehicles [18].

In the literature, different aspects of various Miller cycles have been investigated. Since the lower compression ratio lowers the peak temperature, many studies demonstrate reduced $\mathrm{NO}_{\mathrm{x}}$ emissions e.g.[ㅌ, $\underline{7}, \underline{17}, \underline{19}]$. Another aspect of the system to consider is the need for supercharging during high load [11, 12]. The lower cylinder pressure (i.e. lower gas density) will increase the risk of the spray hitting the wall e.g. [으, $\underline{8}, \underline{20}]$ which could be detected by particulate matter (PM) analysis [13]. Even though many studies report on the importance of spray atomization, most studies keep the injection pressure constant (e.g. [무 $\underline{13}, \underline{21}, \underline{22}, \underline{23}, \underline{24}$ ]. In some cases the injection pressure is varied as a means to vary the load point $[\underline{7}, \underline{17}, \underline{19}]$.

Many studies explore the possibility of having a larger amount of pre-mixed combustion (e.g. [으, 24]) and the effects of EGR to lower both $\mathrm{NO}_{X}$ and peak pressures $[\underline{5}, \underline{9}, \underline{10}, \underline{12}]$.

In this study the effect of LIVC was investigated together with the effect of EGR in a single cylinder heavy duty diesel engine. Different injection timings and injection pressures were investigated at two different load points. The mass flow of oxygen was kept constant in order to show how the physical properties (density and temperature) affect the combustion and emission characteristics.

\section{EXPERIMENTAL}

The engine was a single cylinder heavy duty diesel engine equipped with a common rail injector system (from Delphi) and a VVA system (from Cargine). The EGR was controlled by adjusting the back pressure and in the case of no EGR the back pressure was set equal to the boost pressure, as in [9]. Ultra low sulfur diesel fuel (Swedish MK1) was used throughout this study. The engine details are given in Table 1. The common rail system was pressurized with a pumping injector and can deliver rail pressures up to 3000 bar [25]. The rail pressure, injection timing and duration was controlled by a separate software (ATI Vision).
Table 1. Single cylinder engine and nozzle specifications

\begin{tabular}{|l|l|}
\hline Displacement & $2 \mathrm{dm} 3$ \\
\hline Bore / Stroke & $131 / 150 \mathrm{~mm}$ \\
\hline Geometrical compression ratio & $17: 1$ \\
\hline Nozzle design & 5 hole, $150 \mathrm{deg}$ angle \\
\hline Nozzle flow number & $2.00, \mathrm{~d}_{0}=256 \mu \mathrm{m}$ \\
\hline
\end{tabular}

Two different load points were investigated; one low load (1000rpm, $120 \mathrm{Nm}, 25 \%$ of full load) and one medium load (1500rpm, $180 \mathrm{Nm}, 50 \%$ of full load). In order to isolate the physical properties of the charge air (temperature and density) from chemical property (oxygen concentration), the oxygen flow into the cylinder was kept constant by adjusting the Boost pressure. Other factors affecting the system were explored (by applying factorial designs) over the design space by varying IVC, EGR, injection pressure and timing, see Table 2. The start of injection (SOI) was adjusted to get $50 \%$ burnt (CA50) at three different timings.

Table 2. Evaluated experimental conditions

\begin{tabular}{|l|l|}
\hline Variable & Levels \\
\hline Load points & $1000 \mathrm{rpm} / 120 \mathrm{Nm}, 1500 \mathrm{rpm} / 180 \mathrm{Nm}$ \\
\hline IVC (set values) & $0 ; 40 ; 70 ;(90)$ CADabdc \\
\hline EGR & $0 \% ; 20 \% ; 40 \%$ \\
\hline Pinj & $1500 ; 2400$ bar \\
\hline CA50 & Approx. 2; 5; 8 CADatdc \\
\hline
\end{tabular}

In total, about 120 experiments were performed and a number of intermediate responses were measured along with end performance responses which were fuel consumption (ISFC) and emission $\left(\mathrm{NO}_{\mathrm{X}}, \mathrm{CO}, \mathrm{HC}\right.$ and soot) results.

Emissions $\left(\mathrm{NO}_{\mathrm{X}}, \mathrm{CO} \& \mathrm{HC}\right)$ were measured with an $\mathrm{AVL}$ AMAi60 and the soot was measured with a smoke meter (AVL 415). The rate of heat release was calculated in Osiris (D2T). The fuel consumption was given as ISFC (indicated specific fuel consumption) since compressor work is not included in the system but rail pressure is included (rocker arm driven by the shaft).

\section{RESULTS AND DISCUSSIONS}

\section{Analysis of Effective IVC}

From previous studies [9] comparing early and late IVC, the effect from IVC (as recorded by the sensors) was not completely "symmetrical" and it was reasoned that this effect was due to heat losses. Another explanation could be local inlet pressure effects which can be accounted for e.g. by $\mathrm{He}$ [19] and Doosje [20]. By assuming isentropic compression, the effective IVC (IVC eff $)$, could be estimated by linear regression. One example is shown in. Figure 1 Note that the $\mathrm{IVC}_{\text {eff }}$ is defined as the cylinder volume when the log-scaled cylinder pressure makes a change in slope. This differs from [19, 20] who extrapolated to the intake manifold pressure. By using 
measurements of airflow (as well as estimation of trapped gas at EVC), the gas density and temperature at SOI can be determined. Note that the two methods for extrapolation give the same results, but the present method doesn't rely on inlet pressures measured in a tank upstream the inlet manifold. The temperatures at IVC using this method agreed with simulations of the engine using GT power.
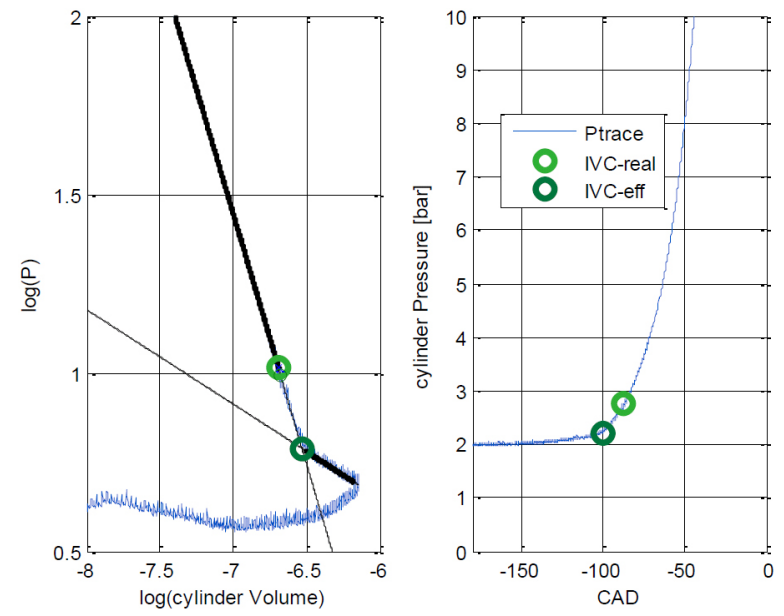

Figure 1. Example of linear regression fit of logarithmic data to obtain the effective IVC (a). Figure (b) shows the same results displaying CAD on the $x$-axis. In this example the boost pressure is 2 bar, the real IVC (measured by sensors) is 93 CADabdc and the effective IVC is 80 CADabdc.

A set of experiments (motoring at 1000rpm) were performed to evaluate the effect on valve lift profile as a function boost pressure and IVC. The results showed that the lift height decreased as the IVC was retarded but boost pressure had minor effect on the IVC, see Fiqure 2.
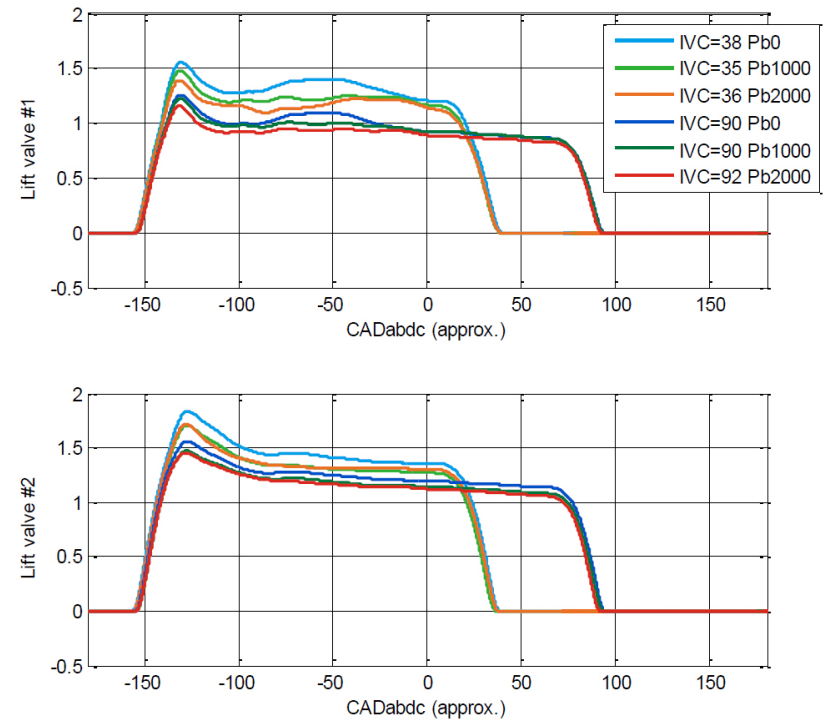

Figure 2. Inlet valve lift height with varying IVC and boost pressure.
The effective IVC (IVC $\left.\mathrm{eff}_{\text {eff }}\right)$ as function IVC and boost pressure is displayed in Figure 3. From Figure 3 , it is clear that IVC $\mathrm{Iff}_{\text {(and }}$ the deviation to the IVC determined from the sensor) is not depending on boost pressure and only slightly depending on IVC.

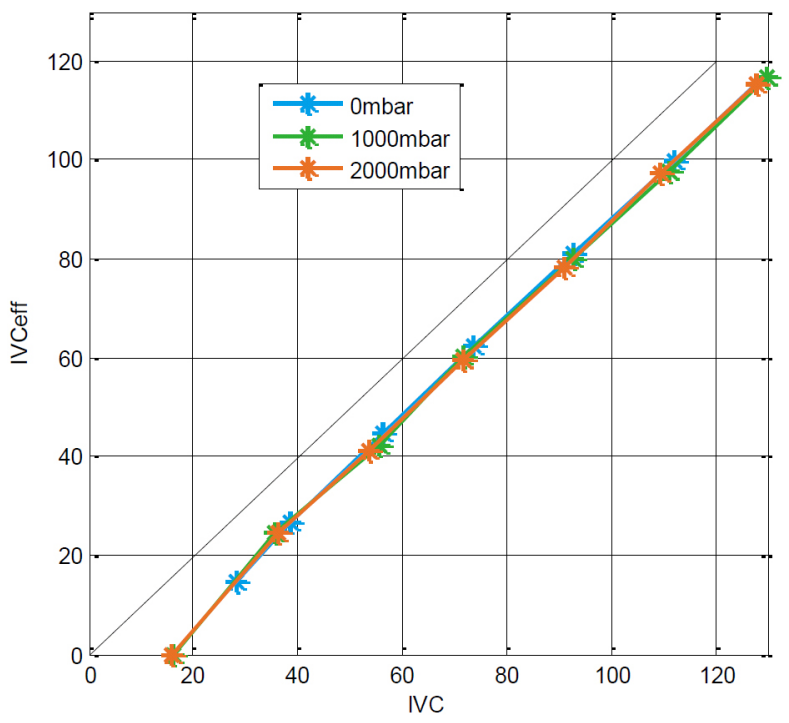

Figure 3. The effective IVC as function of IVC at varying boost pressure.

\section{Analysis of Pressures and Heat Release}

A few examples of Rate of Heat Release (RoHR) are given in Figure 4 (without EGR) and Figure 5 (with EGR). Each set of experiments are shown with similar injection timing at the same engine load point and same injection pressure.

From the experiments without EGR it was shown that later IVC results in more premixed combustion (the first peak of the RoHS is relatively larger than the later part). Since the SOI was chosen to get similar timing (indicated by CA50), the change in fuel consumption was small, but later IVC yields lower fuel consumption.

The RoHR curves for experiments with EGR shows similar sensitivity to IVC. Later IVC gives more pre-mixed combustion. In contrast to the experiments without EGR, late IVC gives higher fuel consumption. The effect is small but may be attributed to combustion temperatures getting too low when applying both EGR and LIVC. Another possible reason is the early combustion resulting in higher cylinder pressure (higher temperatures) and higher heat transfer losses.

For experiments with EGR, it is also interesting to note the correlation between end of injection (EOI) and start of the main combustion peak. This can probably be attributed to entrainment waves as described by Musculus [26]. Even though the combustions in this study can't be classified as pure $\mathrm{PPCl}$ (partially Pre-Mixed Compression Ignition), the application of LIVC in combination with early injections shows some of these features. 

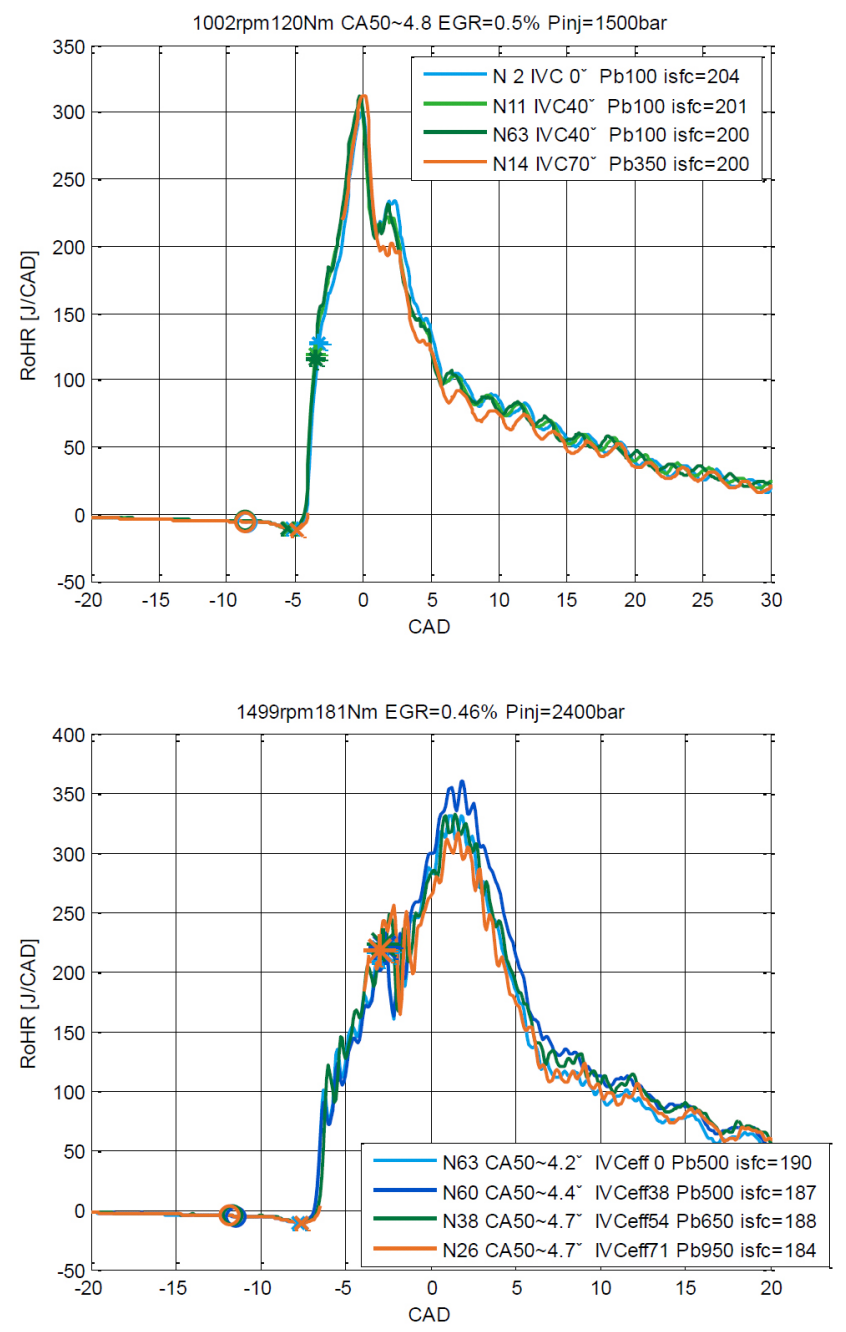

Figure 4. Pressure trace and rate of heat release for experiments without EGR (two different load points). Circles indicate SOI, cross indicates SOC and stars indicates EOI.

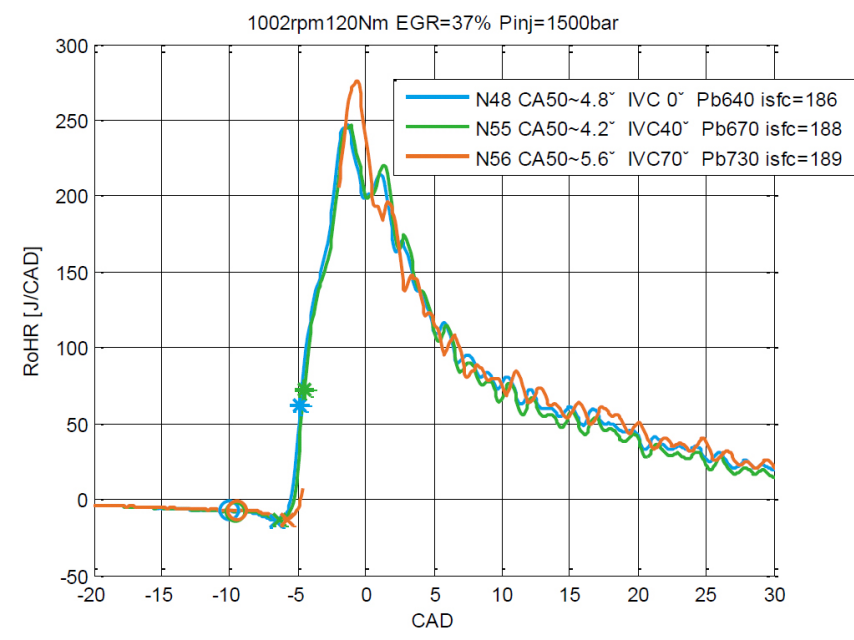

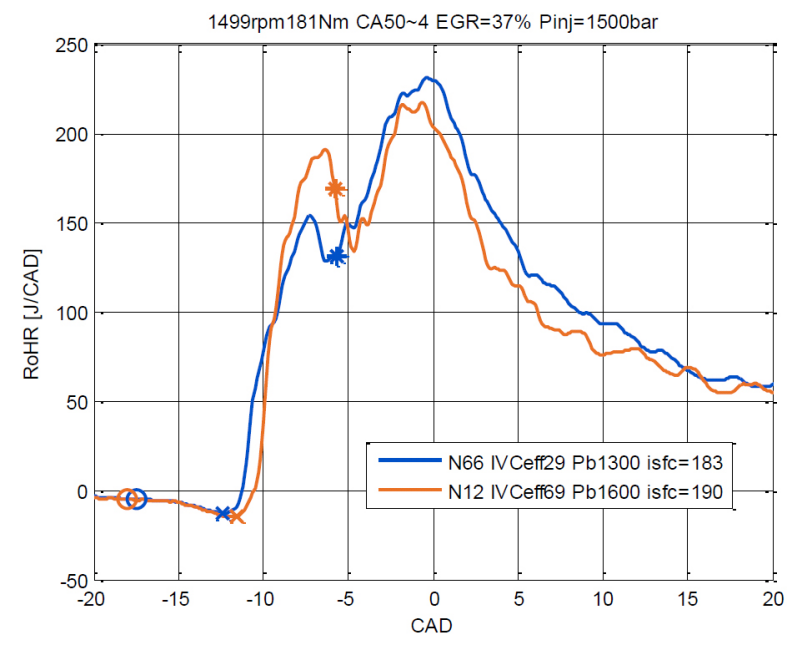

Figure 5. Rate of heat release for experiments with EGR (two different load points). Circles indicate SOI, cross indicates SOC and stars indicates EOI.

\section{Sensitivity of combustion results by change in LIVC} In order to visualize the effect of LIVC, the two load points are compared and EGR vs non-EGR at different injection pressures are compared in the subsequent figures.
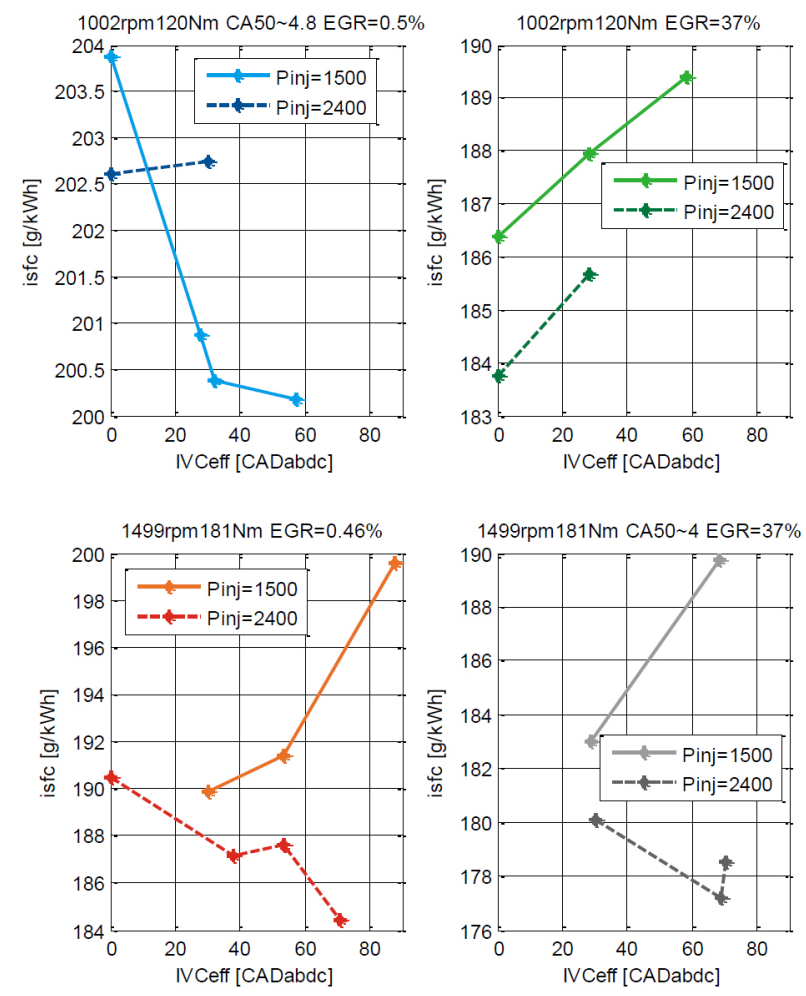

Figure 6. Indicated fuel consumption for two load points and differens amount of EGR and Pinj. 
In Figure 6 it is clear that higher EGR gives lower fuel consumption due to the increased gas charged into the cylinder. The changes in ISFC when varying LIVC are relatively small. However, from Figure 6 it is clear that ISFC does not always decrease with increasing LIVC. One important reason for this is the timing of the combustion. For example, for low load and low $\mathrm{P}_{\text {inj }}$ (blue, upper left figure), the combustion timing is late enough that the increase in LIVC makes the increase in pre-mixed combustion result in a decrease in ISFC. On the other hand, for cases with EGR and low Pinj, the combustion phasing is so early that an increase in pre-mixed combustion results high cylinder pressure, higher temperatures, higher heat transfer losses and consequently increased ISFC.

The $\mathrm{NO}_{x}$ emissions are displayed in Figure 7. Similar to the fuel consumption, the $\mathrm{NO}_{x}$ emissions does not always decrease with an increase in LIVC. In most cases the increase in pre-mixed combustion results in lower temperature for the main combustion and lower $\mathrm{NO}_{x}$ emissions. In some cases however, the combustion timing is early enough that the increase in pre-mixed combustion (in combination with combustion near tdc) has a negative effect on $\mathrm{NO}_{\mathrm{X}}$ emissions.
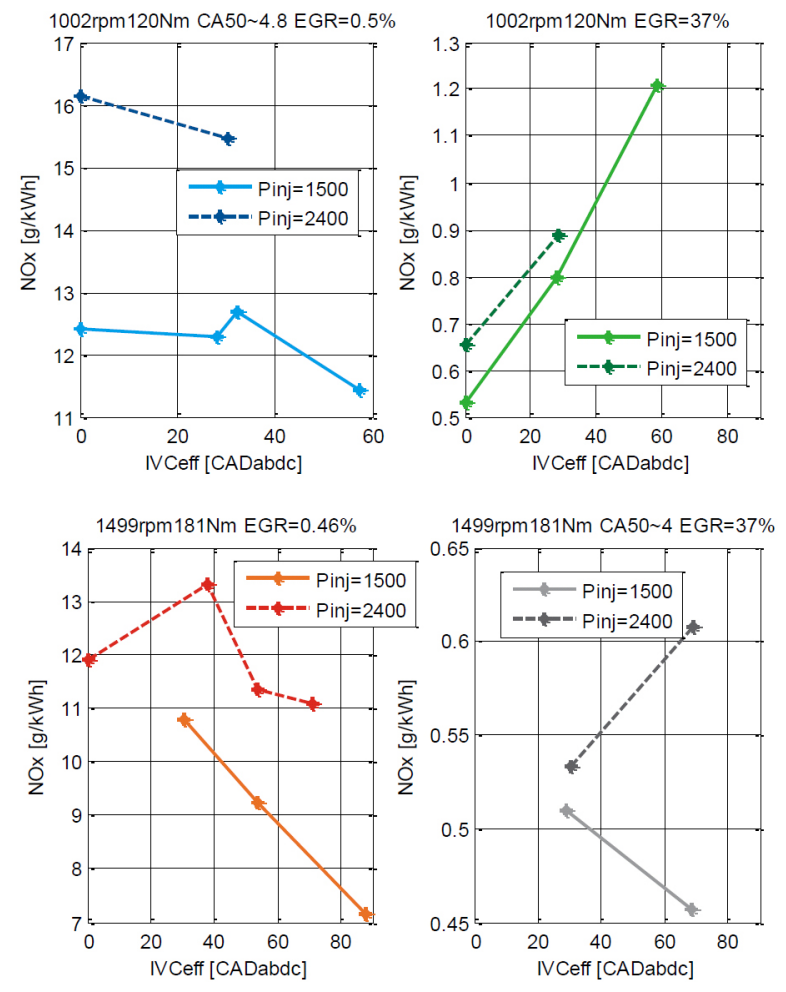

Figure 7. NOX emissions from the two load poins at different levels of EGR and Pinj.
The peak pressures are displayed in Figure 8.
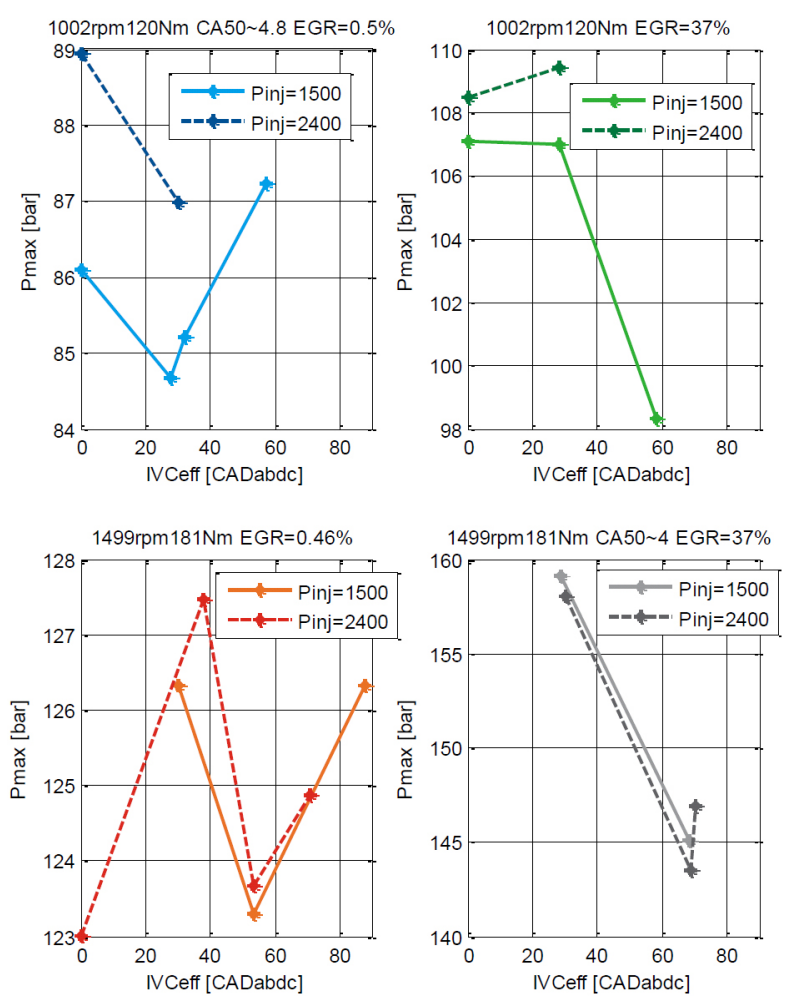

Figure 8. Peak pressures for experiments at two load points and different levels of EGR and Pinj.

In most cases the peak pressure decreases when LIVC is retarded. In some other cases (e.g. for low load, no EGR and low Pinj), the peak pressure increase with increase in LIVC. This can be explained by a slightly higher charge of air, resulting in higher density and a consequent increase in $\mathrm{P}_{\text {max }}$. The relationship between $\mathrm{NO}_{x}$ emission and peak pressure is displayed in Figure 9

In Figure 9 , the $\mathrm{NO}_{\mathrm{x}}$ emissions show a clear dependence on Peak pressure (and thus local max temperature) and EGR $\left(\mathrm{O}_{2}\right.$ concentrations). The range of $\mathrm{NO}_{x}$ emissions is obtained by different courses of combustion (residence times at high temperatures) which were enabled by variations in LIVC.

The ignition delay was assessed by calculating the time from start of injection to start of combustion (as indicated in Figure 4 and Figure 5) and are displayed in Figure 10.

The ignition delay shows very similar values independent of load point or EGR. Note that the experiments selected in this plot had CA50 of about 5 CADatdc, which means that SOI was chosen as to get the desired CA50. As a consequence, the ignition delay is most sensitive to injection pressure and IVC. 

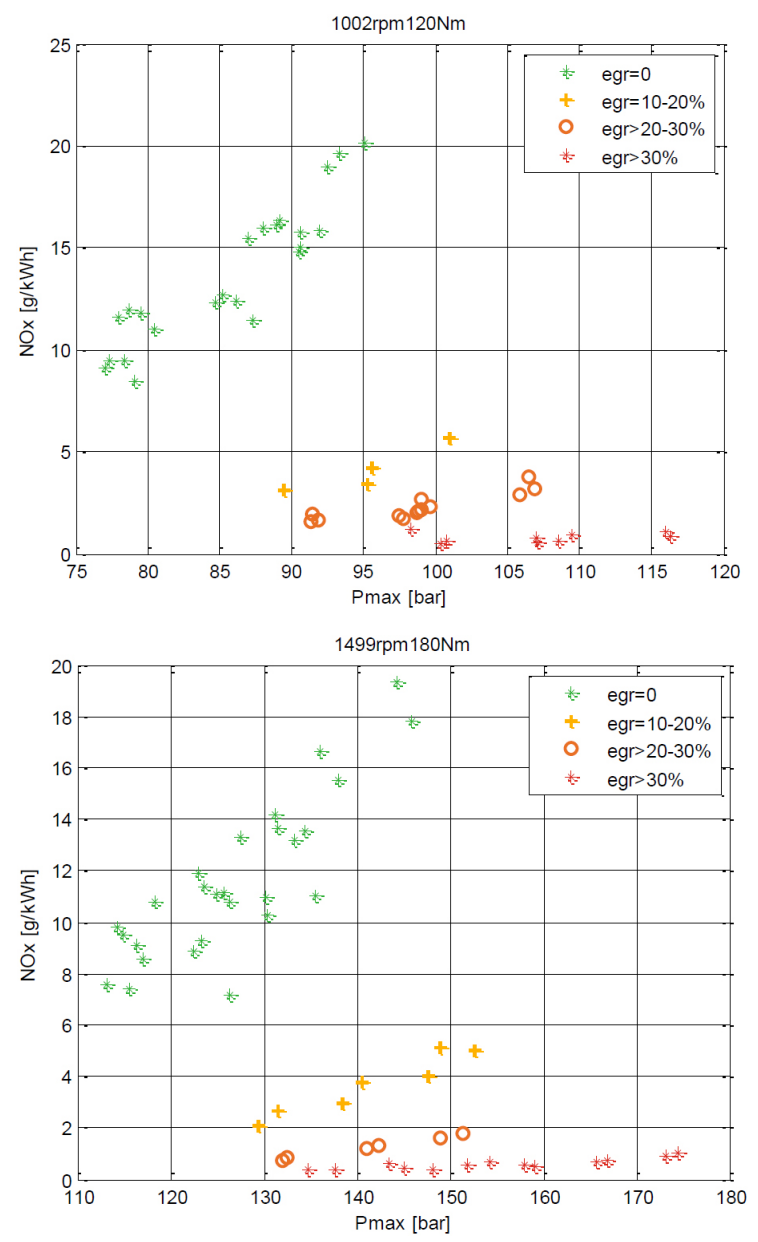

Figure 9. Correlation between Peak pressure (max temperature) and $\mathrm{NO}_{x}$ emissions for different levels of $\mathrm{EGR}\left(\mathrm{O}_{2}\right.$ concentration $)$

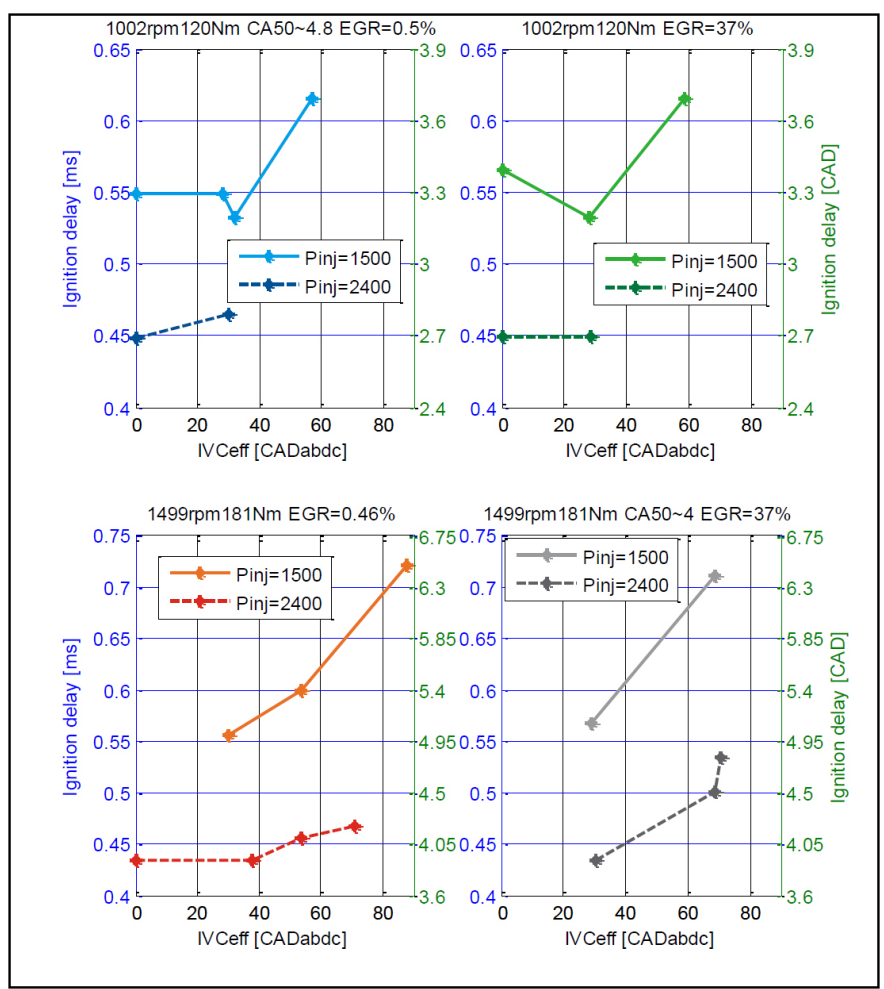

Figure 10. Ignition delay for the two loadponts and for different levels of EGR and Pinj.

\section{SUMMARY \& CONCLUSIONS}

In the presented investigation, LIVC has been explored by varying most engine parameters except $\mathrm{O}_{2}$ flow. The indications from this approach are that higher EGR requires higher charge gas flow which gives better efficiency. From the experiments performed here, one might be tempted to conclude that EGR is a more efficient means to reduce ISFC than LIVC, but the current experimental setup cannot prove this conclusion since the EGR is highly correlated with the gas flow. This issue is presently under investigation. The sensitivity of the results for IVC at different load points when supplied with different levels of EGR and injection pressures indicates that the combustion timing is an important parameter when assessing the effect of LIVC. Here, combustion near TDC has been presented and the balance of pre-mixed combustion and combustion before TDC is delicate. Even though combustion phasing (as defined by CA50) was almost constant the effects of LIVC was not constant. This shows that general statements of the effect of LIVC cannot be made without also describing the combustion characteristics (e.g. amount of pre-mixed combustion before TDC).

The results show that the combustion characteristics are very sensitive to LIVC. In combination with turbo charging and EGR, the use of LIVC enables independent control of the charge density, temperature and oxygen concentration. Therefor LIVC can be an important tool for optimizing future powertrains.

\section{REFERENCES}

1. Miller, R., "Supercharged engine", US Patent US2817322 A, 1957

2. CORE, EU-project, GA SCP1-GA-2012-284909, 2011, www. CO2re.eu

3. Heywood, J.B., "Ideal models of engine cycles", in "Internal Combustion Engine Fundamentals", McGraw-Hill, Singapore, ISBN 0-07-100499-9, 1988

4. Ebrahimi, R., "Performance analysis of an irreversible Miller cycle with considerations of relative air-fuel ratio and stroke length", Applied Mathematical Modelling, 36(9): 4073-4079, 2012, doi:10.1016/j.apm.2011.11.031.

5. Hatamura, K., Hayakawa M., Goto T. and Hitomi M., "A study of the improvement effect of Miller-cycle on mean effective pressure limit for high-pressure supercharged gasoline engines", JSAE Review, 18(2): 101-106, 1997, doi:10.1016/S03894304(96)00069-0.

6. Murata, Y., Nishio Y., Kusaka J., Daisho Y., et al., "Numerical analysis of Miller-premixed charge compression ignition combustion on a dynamic phi-T map", International Journal of Engine Research, 11(2): 89-98, 2010.

7. Imperato, M., Antila, E., Sarjovaara, T., Kaario, O. et al., " $\mathrm{NO}_{\mathrm{x}}$ Reduction in a Medium-Speed Single-Cylinder Diesel Engine using Miller Cycle with Very Advanced Valve Timing," SAE Technical Paper 2009-24-0112, 2009, doi:10.4271/2009-24-0112.

8. Brijesh, P. and Sreedhara S., "Exhaust emissions and its control methods in compression ignition engines: A review", International Journal of Automotive Technology, 14(2): 195-206, 2013, doi:10.1007/s12239-013-0022-2.

9. Ehleskog, M., Gjirja, S., and Denbratt, I., "Effects of Variable Inlet Valve Timing and Swirl Ratio on Combustion and Emissions in a Heavy Duty Diesel Engine," SAE Technical Paper 2012-01-1719, 2012, doi: $10.4271 / 2012-01-1719$.

10. Edwards, S., Frankle, G., Wirbeleit, F., and Raab, A., "The Potential of a Combined Miller Cycle and Internal EGR Engine for Future Heavy Duty Truck Applications," SAE Technical Paper 980180, 1998, doi: $\underline{10.4271 / 980180}$. 
11. Millo, F., Mallamo, F., and Mego, G., "The Potential of Dual Stage Turbocharging and Miller Cycle for HD Diesel Engines," SAE

Technical Paper 2005-01-0221, 2005, doi:10.4271/2005-01-0221.

12. Millo, F., Gianoglio Bernardi, M., and Delneri, D., "Computational Analysis of Internal and External EGR Strategies Combined with Miller Cycle Concept for a Two Stage Turbocharged Medium Speed Marine Diesel Engine," SAE Int. J. Engines 4(1):1319 1330, 2011, doi:10.4271/2011-01-1142.

13. Benajes, J., Novella, R., Arthozoul, S., and Kolodziej, C., "Particle Size Distribution Measurements from Early to Late Injection Timing Low Temperature Combustion in a Heavy Duty Diesel Engine," SAE Int. J. Fuels Lubr. 3(1):567-581, 2010, doi:10.4271/2010-01-1121.

14. Benajes, J., Molina S., Martín J. and Novella R., "Effect of advancing the closing angle of the intake valves on diffusioncontrolled combustion in a HD diesel engine", Applied Thermal Engineering, 29(10): 1947-1954, 2009, doi:10.1016/j. applthermaleng.2008.09.014.

15. Martins, J., Uzuneanu, K., Ribeiro, B., and Jasasky, O., "Thermodynamic Analysis of an Over-Expanded Engine," SAE Technical Paper 2004-01-0617, 2004, doi:10.4271/2004-01-0617.

16. Ribeiro, B. and Martins, J., "Direct Comparison of an Engine Working under Otto, Miller and Diesel Cycles: Thermodynamic Analysis and Real Engine Performance," SAE Technical Paper 2007-01-0261, 2007, doi:10.4271/2007-01-0261.

17. Heikkilä, J., Happonen M., Murtonen T., Lehto K., et al., "Study of Miller timing on exhaust emissions of a hydrotreated vegetable oil (HVO)-fueled diesel engine", Journal of the air \& waste management association, 62(11): 1305-1312, 2012, doi:10.1080/1 $\underline{0962247.2012 .708383}$.

18. Higuchi, N., Sunaga, Y., Tanaka, M., and Shimada, H., "Development of a New Two-Motor Plug-In Hybrid System," SAE Int. J. Alt. Power. 2(1):135-145, 2013, doi:10.4271/2013-01-1476.

19. He, X., Durrett, R., and Sun, Z., "Late Intake Valve Closing as an Emissions Control Strategy at Tier 2 Bin 5 Engine-Out NOx Level," SAE Int. J. Engines 1(1):427-443, 2009, doi:10.4271/200801-0637.

20. Doosje, E., Willems, F., Baert, R., and Van Dijk, M., "Experimental Study into a Hybrid PCCl/Cl Concept for Next-Generation HeavyDuty Diesel Engines," SAE Technical Paper 2012-01-1114, 2012, doi:10.4271/2012-01-1114.

21. De Ojeda, W., "Effect of Variable Valve Timing on Diesel Combustion Characteristics," SAE Technical Paper 2010-01-1124, 2010, doi:10.4271/2010-01-1124.

22. Wu, B., Yu, H., Pak, P., Pei, Y. et al., "Effects of Late Intake Valve Closing Timing on Thermal Efficiency and Emissions Based on a Two-stage Turbocharger Diesel Engine," SAE Technical Paper 2013-01-0276, 2013, doi:10.4271/2013-01-0276.

23. Benajes, J., Serrano J.R., Molina S. and Novella R., "Potential of Atkinson cycle combined with EGR for pollutant control in a HD diesel engine", Energy Conversion and Management, 50(1): 174183, 2009, doi:10.1016/j.enconman.2008.08.034.

24. Murata, Y., Kusaka, J., Daisho, Y., Kawano, D. et al., "Miller-PCCI Combustion in an HSDI Diesel Engine with VVT," SAE Int. J. Engines 1(1):444-456, 2009, doi:10.4271/2008-01-0644.

25. Delphi. "Delphi F2e Ultra High Pressure Heavy Duty Diesel Common Rail System". 2014 [cited 2014 2014-04-23]; F2 common rail system]. Available from: http://delphi.com/ manufacturers/cv/powertrain/common-rail-systems/f2-distributedpump-diesel/.

26. Musculus, M.P.B., Miles P.C. and Pickett L.M., "Conceptual models for partially premixed low-temperature diesel combustion", Progress in Energy and Combustion Science, 39(2-3): 246-283, 2013, doi:10.1016/j.pecs.2012.09.001.

\section{CONTACT INFORMATION}

Jonas Sjöblom

Applied Mechanics

division of Combustion

Chalmers University of Technology

SE-412 96 Gothenburg, Sweden

phone: +46-31-772 1389

jonas.sjoblom@chalmers.se

\section{ACKNOWLEDGMENTS}

Savo Girja is greatly acknowledged for running the engine during the experimetns. Work has been carried out as a part of CORE (SCP1-GA-2012-284909), a R\&D project funded by European Commission.

\section{DEFINITIONS/ABBREVIATIONS}

\author{
atdc/ abdc - After / Before top dead center \\ CA50 - 50\% of total heat release \\ CAD - Crank Angle Degrees \\ $\mathbf{c r}_{\text {eff }}$ - Effective compression ratio \\ EGR - Exhaust Gas Recirculation \\ EOI - End of Injection \\ IMEP - Indicated mean effective pressure \\ ISFC - Indicated specific fuel consumption

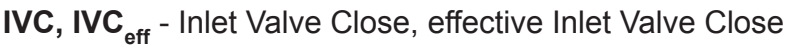 \\ LIVC - Late Inlet Valve closing \\ Pinj - (rail) Injection Pressure \\ PPCI - Partially Pre-mixed Compression Ignition \\ RoHR - Rate of Heat Release \\ SOC - Start of Combustion \\ SOI - Start of Injection \\ tdc, bdc - top dead centre, bottom dead centre
}




\section{APPENDIX}

Table 3. Table of the data used for figures $4, \underline{5}, \underline{6}, \underline{7}, \underline{8} \& \underline{10}$ as well as additional information. CAD refers to CADatdc unless otherwise specified.

\begin{tabular}{|c|c|c|c|c|c|c|c|c|c|c|c|c|c|c|c|c|c|c|c|c|c|c|c|}
\hline id & $\mathrm{N}$ & $\mathrm{T}$ & Pboost & $P_{\text {exh }}$ & EGR & IVC & $\mathrm{IVC}_{\text {eff }}$ & $\mathrm{Cr}_{\text {eff }}$ & $\mathrm{O}_{2}$ flow & gasflow & $P_{\text {inj }}$ & sol & EOI & soc & IgnDel & CA10 & CA50 & CA9O & ISFC & NOx & $\mathrm{HC}$ & co & SOOT \\
\hline & $\mathrm{rpm}$ & $\mathrm{Nm}$ & mbar & mbar & $\%$ & CADabdc & CADabdc & - & $\mathrm{kg} / \mathrm{h}$ & $\mathrm{kg} / \mathrm{h}$ & bar & CAD & CAD & CAD & ms & CAD & CAD & CAD & $\mathrm{g} / \mathrm{kWh}$ & g/kWh & g/kWh & g/kWh & $\mathrm{g} / \mathrm{kWh}$ \\
\hline $1-2$ & 1002 & 121 & 100 & 100 & 1 & 1 & 0 & 17.0 & 17 & 83 & 1500 & -8.5 & -3.3 & -5.2 & 0.5 & -1.3 & 4.9 & 27.8 & 203.9 & 12.4 & 9.23 & 0.96 & $\mathrm{NaN}$ \\
\hline $1-11$ & 1003 & 120 & 100 & 100 & 0 & 42 & 28 & 16.3 & 17 & 81 & 1500 & -8.7 & -3.6 & -5.4 & 0.5 & -1.5 & 4.9 & 28.3 & 200.9 & 12.3 & 3.23 & 0.67 & 0.00 \\
\hline $1-14$ & 1002 & 120 & 350 & 350 & 1 & 70 & 57 & 14.2 & 18 & 86 & 1500 & -8.6 & -3.5 & -4.9 & 0.6 & -1.1 & 4.8 & 28.0 & 200.2 & 11.4 & 2.35 & 0.53 & 0.00 \\
\hline $1-63$ & 1002 & 120 & 100 & 100 & 0 & 42 & 32 & 16.1 & 16 & 78 & 1500 & -8.7 & -3.5 & -5.5 & 0.5 & -1.5 & 4.8 & 28.4 & 200.4 & 12.7 & 0.30 & 0.60 & 0.01 \\
\hline $1-48$ & 1002 & 121 & 640 & 790 & 41 & 0 & 0 & 17.0 & 17 & 112 & 1500 & -10.0 & -4.9 & -6.6 & 0.6 & -2.2 & 4.8 & 28.3 & 186.4 & 0.5 & 0.35 & 2.30 & 0.21 \\
\hline $1-55$ & 1003 & 119 & 670 & 810 & 38 & 40 & 28 & 16.3 & 18 & 112 & 1500 & -9.6 & -4.5 & -6.4 & 0.5 & -2.1 & 4.2 & 25.3 & 188.0 & 0.8 & 0.42 & 1.53 & 0.09 \\
\hline $1-56$ & 1003 & 119 & 730 & 840 & 31 & 70 & 59 & 14.0 & 17 & 102 & 1500 & -9.5 & \begin{tabular}{|l|}
-4.4 \\
\end{tabular} & $\begin{array}{l}-5.8 \\
\end{array}$ & 0.6 & -1.5 & 5.6 & 29.3 & 189.4 & 1.2 & 0.17 & 1.07 & 0.06 \\
\hline $1-5$ & 1003 & 120 & 100 & 100 & 0 & 0 & 0 & 17.0 & 17 & 83 & 2400 & -6.5 & -2.5 & -3.8 & 0.4 & -0.5 & 4.9 & 25.5 & 202.6 & 16.1 & 3.46 & 0.42 & 0.00 \\
\hline $1-8$ & 1003 & 121 & 100 & 100 & 0 & 41 & 30 & 16.2 & 17 & 81 & 2400 & -6.5 & -2.4 & -3.7 & 0.5 & -0.5 & 4.8 & 25.3 & 202.7 & 15.5 & 3.71 & 0.54 & 0.00 \\
\hline $1-49$ & 1002 & 119 & 640 & 790 & 40 & 1 & 0 & 17.0 & 17 & 112 & 2400 & -7.6 & -3.8 & -4.9 & 0.4 & -1.1 & 4.5 & 24.6 & \begin{tabular}{ll|}
183.8 \\
\end{tabular} & 0.7 & 0.31 & 0.93 & 0.06 \\
\hline $1-54$ & 1002 & 120 & 670 & 810 & 38 & 40 & 28 & 16.3 & 17 & 111 & 2400 & -7.6 & -3.7 & -4.9 & 0.4 & -1.2 & 4.3 & 23.6 & 185.7 & 0.9 & 0.17 & 0.68 & 0.03 \\
\hline $2-31$ & 1500 & 181 & 1200 & 1200 & 0 & 106 & 88 & 10.5 & 31 & 148 & 1500 & -18.0 & $\begin{array}{l}-5.4 \\
\end{array}$ & -11.5 & 0.7 & -6.4 & 2.9 & 35.4 & 199.6 & 7.2 & 0.03 & 4.08 & 0.07 \\
\hline $2-35$ & 1499 & 181 & 650 & 650 & 0 & 70 & 54 & 14.5 & 32 & 152 & 1500 & -15.0 & \begin{tabular}{|l|}
-3.1 \\
\end{tabular} & -9.6 & 0.6 & -4.7 & 4.0 & 31.1 & $\begin{array}{l}191.4 \\
\end{array}$ & 9.2 & 1.15 & 1.41 & 0.02 \\
\hline $2-55$ & 1499 & 180 & 500 & 500 & 0 & 41 & 30 & 16.2 & 32 & 155 & 1500 & -14.6 & -3.0 & -9.6 & 0.6 & $\begin{array}{l}-4.3 \\
\end{array}$ & 4.0 & 29.1 & 189.9 & 10.8 & 0.30 & 0.97 & 0.01 \\
\hline $2-12$ & 1500 & 180 & 1600 & 1660 & 34 & 86 & 69 & 12.9 & 29 & 188 & 1500 & -18.0 & -5.9 & -11.6 & 0.7 & -6.4 & 4.1 & 34.7 & 189.7 & 0.5 & 0.12 & $\mathrm{NaN}$ & 1.74 \\
\hline $2-66$ & 1499 & 181 & 1300 & 1400 & 39 & 41 & 29 & 16.3 & 32 & 211 & 1500 & -17.5 & -5.8 & -12.4 & 0.6 & -6.2 & 3.9 & 31.3 & 183.0 & 0.5 & 0.21 & 11.0 & $\mathrm{NaN}$ \\
\hline $2-26$ & 1499 & 181 & 950 & 950 & 0 & 90 & 71 & 12.6 & 33 & 157 & 2400 & -11.8 & -3.1 & -7.6 & 0.5 & -2.6 & 4.7 & 29.8 & 184.5 & 11.1 & 0.30 & 0.49 & $\mathrm{NaN}$ \\
\hline $2-38$ & 1499 & 181 & 650 & 650 & 0 & 72 & 54 & 14.5 & 31 & 149 & 2400 & -11.7 & -2.9 & -7.6 & 0.5 & -2.8 & 4.7 & 29.4 & 187.6 & 11.4 & 0.28 & 0.77 & 0.01 \\
\hline $2-60$ & 1499 & 181 & 500 & 500 & 0 & 39 & 38 & 15.8 & 32 & 153 & 2400 & -11.5 & -2.8 & -7.6 & 0.4 & -2.7 & 4.4 & 26.9 & 187.2 & 13.3 & 0.20 & 0.50 & 0.00 \\
\hline $2-63$ & 1499 & 180 & 500 & 500 & 0 & 2 & 0 & 17.0 & 30 & 146 & 2400 & -11.7 & -2.9 & -7.8 & 0.4 & $\begin{array}{l}-2.9 \\
\end{array}$ & 4.2 & 28.8 & 190.5 & 11.9 & 0.17 & 0.96 & 0.01 \\
\hline $2-8$ & 1498 & 180 & 1600 & 1660 & 32 & 88 & 71 & 12.7 & 30 & 187 & 2400 & -14.5 & \begin{tabular}{|l|}
-5.8 \\
\end{tabular} & $\begin{array}{l}-9.7 \\
\end{array}$ & 0.5 & -4.6 & 4.0 & 31.5 & 178.5 & $\mathrm{NaN}$ & 0.05 & 4.19 & 0.24 \\
\hline $2-9$ & 1499 & 180 & 1600 & 1660 & 34 & 86 & 69 & 12.9 & 30 & 194 & 2400 & -13.0 & \begin{tabular}{|l|}
-4.4 \\
\end{tabular} & $\begin{array}{l}-8.5 \\
\end{array}$ & 0.5 & -3.0 & 5.7 & 33.0 & $\begin{array}{l}177.2 \\
\end{array}$ & 0.6 & 0.19 & 5.84 & 0.45 \\
\hline $2-69$ & 1499 & 180 & 1300 & 1400 & 39 & 39 & 30 & 16.2 & 31 & 207 & 2400 & -13.8 & $\begin{array}{l}-5.2 \\
\end{array}$ & \begin{tabular}{|l|}
-9.9 \\
\end{tabular} & 0.4 & -4.3 & 4.1 & 29.3 & 180.1 & 0.5 & 0.13 & 6.08 & $\mathrm{NaN}$ \\
\hline
\end{tabular}

All rights reserved. No part of this publication may be reproduced, stored in a retrieval system, or transmitted, in any form or by any means, electronic, mechanical, photocopying, recording, or otherwise, without the prior written permission of SAE International.

Positions and opinions advanced in this paper are those of the author(s) and not necessarily those of SAE International. The author is solely responsible for the content of the paper. 